\title{
APAKAH KEBIJAKAN REKRUTMEN PESERTA DIDIK DAN MANAJEMEN SARANA PRASARANA BERPENGARUH TERHADAP PRESTASI BELAJAR SISWA SEKOLAH MENENGAH ATAS?
}

\author{
Hendi Rohaendi \\ SMA Negeri 1 Anjatan Indramayu- Jawa Barat, hendirohaendi1971hh@gmail.com
}

Received January 27, 2020, reviewed februari 3, 2020, published apr 30, 2020

Citation: Rohendi, H. (2020). Apakah kebijakan rekrutmen peserta didik dan manajemen sarana prasarana berpengaruh terhadap prestasi belajar siswa Sekolah Menengah Atas?. Edum Journal, 3(1)

\begin{abstract}
ABSTRAK
Tujuan dalam penelitian ini adalah untuk memperoleh gambaran aktual mengenai pengaruh kebijakan rekrutmen peserta didik dan manajemen sarana prasarana terhadap prestasi belajar siswa di SMA. Metode penelitian yang dipakai pada penelitian ini adalah survei dengan pendekatan kuantitatif. Partisipan yang terlibat dalam penelitian ini sebanyak 60 orang. Selain itu teknik pengumpulan data menggunakan angket tertutup. Teknik analisis data hasil penelitian menggunakan statistik deskriptif, regresi sederhana, dan regresi berganda. Hasil penelitian menunjukkan bahwa: (1) Terdapat pengaruh yang positif dan signifikan dari variabel rekrutmen peserta didik $\left(\mathrm{X}_{1}\right)$ terhadap prestasi belajar siswa (Y) sebesar 2,4\%. (2) Terdapat pengaruh yang positif dan siginifikan dari variabel manajemen sarana prasarana $\left(\mathrm{X}_{2}\right)$ terhadap prestasi belajar siswa $(\mathrm{Y})$ sebesar 60,5\%, dan (3) Terdapat pengaruh yang positif dan signifikan dari variabel rekrutmen peserta didik $\left(\mathrm{X}_{1}\right)$ dan manajemen sarana prasarana $\left(\mathrm{X}_{2}\right)$ secara bersama-sama terhadap prestasi belajar siswa $(\mathrm{Y})$ sebesar $60,7 \%$. Berdasarkan penelitian ini disarankan untuk meningkatan pelayanan dalam kegiatan rekrutmen peserta didik dan peningkatan dalam pengelolaan manajemen sarana prasarana demi untuk meningkatkan hasil prestasi belajar siswa sesuai dengan harapan orang tua dan tujuan sekolah.
\end{abstract}

Kata Kunci: Rekrutmen Peserta Didik, Manajemen Sarana Prasarana, Prestasi Belajar Siswa

\section{ABSTRACT}

The purpose of this study is to obtain an actual picture of the influence of student recruitment policies and management of infrastructure on student achievement in high school. The research method used in this study is a survey with a quantitative approach. Participants involved in this study were 60 people. In addition, data collection techniques use a closed questionnaire. Data analysis techniques of the results of the study used descriptive statistics, simple regression, and multiple regression. The results showed that: (1) There was a positive and significant effect of the student recruitment variable $\left(\mathrm{X}_{1}\right)$ on student achievement $(\mathrm{Y})$ of $2.4 \%$. (2) There is a positive and significant influence of the infrastructure management variable $\left(\mathrm{X}_{2}\right)$ on student achievement $(\mathrm{Y})$ of $60.5 \%$, and (3) There is a positive and significant influence on the variable of student recruitment $\left(\mathrm{X}_{1}\right)$ and management infrastructure $\left(\mathrm{X}_{2}\right)$ together towards student learning achievement $(\mathrm{Y})$ of $60.7 \%$. Based on this research it is recommended to improve services in student recruitment activities and improvement in the management of infrastructure facilities in order to improve student achieve

Keywords: Students' recruitment, Infrastructure management, Students' achievement

\section{PENDAHULUAN}

Keberhasilan

dalam

penyelenggaraan lembaga sekolah akan

sangat bergantung kepada manajemen, komponen-komponen

pendukung

pelaksanaan kegiatan seperti kurikulum,

peserta didik, pembiayaan, tenaga

pelaksana, dan sarana prasarana. 
(Hamidah, 2018). Untuk menjaga agar sekolah memiliki citra yang baik dalam pandangan masyarakat, maka perlu dilakukan perbaikan kualitas pelayanan (Dekawati, 2018). Oleh karena itu, sekolah merupakan suatu sistem organisasi yang memudakan pencapaian tujuan belajar dan mengajar secara efisien dan efektif (Amran, 2015).

Salah satu aktivtas sekolah yakni melakukan rekrutmen peserta didik. Rekrutmen sekolah dalam tinjauan manajemen penyelenggaran pendidikan formal (persekolahan) merupakan kegiatan rutin yang dilakukan oleh sekolah untuk menghimpun, menyeleksi, dan menempatkan calon peserta didik menjadi peserta didik pada jenjang dan jalur pendidikan tertentu.

Berdasarkan penelusuran peneliti pada sekolah menengah atas (SMA) negeri di K3S V wilayah Haurgeulis Kabupaten Indramayu, terdapat permasalahan yang berhubungan dengan rekrutmen peserta didik diantaranya ketidaktercapainnya jumlah rombel (rombongan belajar) yang disediakan dinas pendidikan pemerintah provinsi jawa barat dengan jumlah siswa yang melamar untuk diterima sebagai peserta didik baru.

Hal yang lain terkait dengan sarana dan prasarana sebagai bagian integral dari keseluruhan kegiatan pembelajaran di satuan pendidikan mempunyai fungsi dan peran dalam pencapaian kegiatan pembelajaran sesuai kurikulum satuan pendidikan (Prastyawan, 2016). Agar pemenuhan sarana dan prasarana tepat guna dan berdaya guna (efektif dan efisien), diperlukan suatu analisis kebutuhan yang tepat di dalam perencanaan pemenuhannya (Prastyawan, 2016). Administrasi sarana dan prasarana pendidikan adalah semua komponen yang secara langsung maupun tidak langsung menunjang jalannya proses pendidikan untuk mencapai tujuan dalam pendidikan itu sendiri (Rosivia, 2014).

Berdasarkan hasil penelitian berkaitan kebijakan rekrutmen peserta didik dan sarana prasarana dan dampaknya terhadap prestasi siswa seperti Pratomo, Suwitri \& Subowo (2013) melakukan analisis terhadap kebijakan rekrutmen di SMP dan menyimpulkan bahwa rekrutemen yang baik akan berdampak positif terhdap prestasi akademik peserta didik di sekolah. Sedangkan menurut eferi perlu adanya Strategi-strtegi dalam melakukan Rekrutmen Peserta Didik Baru agar dapat Meningkatkan Keunggulan Kompetitif sekolah.

Selain itu berkaitan dengan sarana dan prasarana menurut dekawati (2018) 
menyimpilkan bahwa Pengelolaan sarana prasarana memiliki kontribusi signifikan terhadap mutu pelayanan pendidikan. Selain itu menurut Putri \& Adi (2016) menyimpulkan bahwa sarana dan prasarana berpengaruh terhadap prestasi belajar siswa.

Berdasarkan temuan-temuan tersebut, penelitian ini akan menganlisis pengaruh kebijakan rekrutemen peserta didik dan sarana prasarana terhadap prestasi peserta didik di salah satu sub rayon yang ada Kabupaten Indramayu.

\section{METODELOGI PENELITIAN}

Metode penelitian yang dipakai pada penelitian ini adalah survei dengan pendekatan kuantitatif. Penelitian survei yang dimaksud adalah bersifat menjelaskan hubungan kausal antar variabel dan pengujian hipotesis, yaitu variabel bebas terhadap variabel terikat, yaitu kebijakan rekrutmen peserta didik $\left(\mathrm{X}_{1}\right)$ dan manajemen sarana prasarana $\left(\mathrm{X}_{2}\right)$ terhadap prestasi belajar siswa (Y). Uji Validitas digunakan rumus Product Moment Correration dari Karl Pearson dan Uji Reliabitas digunakan Rumus Alfa Cronbach dari Spearman Brown

Populasi penelitian ini adalah guru SMA Negeri di K3S V wilayah Haurgeulis Kabupaten Indramayu yang jumlah gurunya sebanyak 155 orang, yang tersebar di empat kecamatan, yaitu: Sukra, Anjatan,Haurgeulis, dan Gantar. Penentuan sampel penelitian dilakukan dengan menggunakan rumus Slovin diperoleh sampel sebanyak 60 orang.

Variabel dalam penelitian ini terdiri dari dua variabel, diantaranya variabel bebas (independent variabel) dengan notasi $\left(\mathrm{X}_{1}\right)$ untuk kebijakan rekrutmen peserta didik dan $\left(\mathrm{X}_{2}\right)$ untuk manajemen sarana prasarana, dan satu buah variabel terikat (dependent variabel) dengan notasi (Y) untuk prestasi belajar siswa.

Angket dalam penelitian ini dimaksudkan untuk mendapatkan data yang menyangkut kebijakan rekrutmen peserta didik $\left(\mathrm{X}_{1}\right)$, Manajemen sarana prasarana $\left(\mathrm{X}_{2}\right)$, dan prestasi belajar siswa (Y). Teknik pengumpulan data tidak langsung yaitu dengan mengadakan komunikasi dengan subyek penelitian melalui perantara instrumen. Peneliti melakukan penelitian langsung di lapangan untuk memperoleh data yang diperlukan, dalam penelitian ini peneliti menggunakan: (a) Interview (Wawancara); (b) Observasi (Pengamatan); (c) Kuesioner (Angket). Teknik analisis data yang digunakan yakni teknik Analisis Deskritif dan inferensial. Analisis infersensial yang digunakan menggunakan analsisis regresi sederhana dan berganda. 


\section{HASIL PENELITIAN DAN PEMBAHASAN}

\section{Hasil Penelitian}

Penelitian ini bertujuan mengetahui besaran pengaruh kebijakan rekrutmen peserta didik dan manajemen sarana prasarana terhadap prestasi belajar siswa, baik secara parsial maupun ganda. Untuk mengetahui besaran pengaruh masingmasing variabel kebijakan rekrutmen peserta didik $\left(\mathrm{X}_{1}\right)$ terhadap prestasi belajar siswa (Y) dilakukan dengan uji regresi linear dengan menggunakan SPSS version 22 for window

Tabel 1 Koefisien Regresi dan Uji signifikansi secara Parsial $X_{1}$

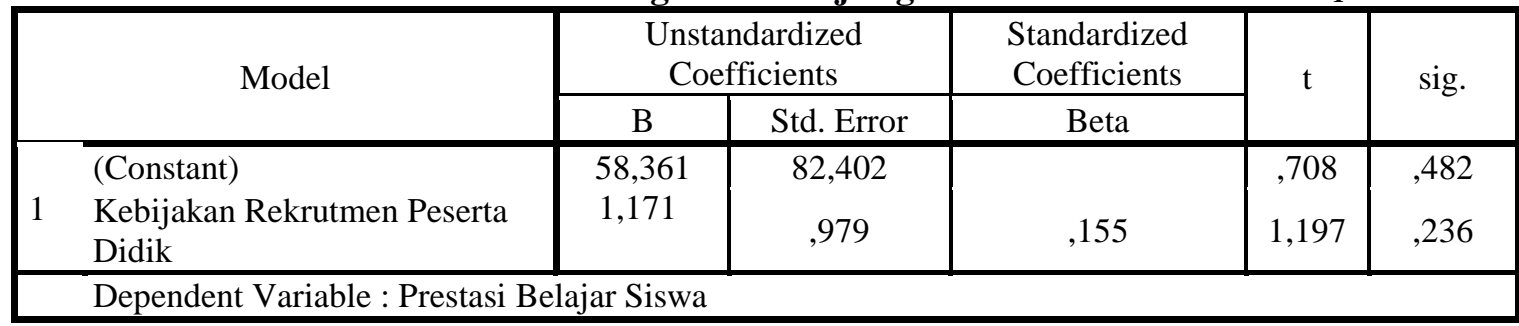

Persamaan regresi dari hasil perhitungan diperoleh $\widehat{y}=\mathrm{a}+\mathrm{bx}$, atau $\widehat{y}==58,361+1,171 X_{1}$. Konstanta sebesar 58,361 menyatakan bahwa jika tidak ada kenaikan nilai dari variabel kebijakan rekrutmen peserta didik $\left(\mathrm{X}_{1}\right)$, maka prestasi belajar siswa adalah

58,361. Koefisien regresi 1,171 menyatakan bahwa setiap perubahan satu skor nilai kebijakan rekrukmen peserta didik maka akan memberikan kenaikan skor kinerja guru sebesar 1,171 unit. Kemudian pengujian signifikansi dilakukan dengan memperhatikan data pada tabel 1 diketahui angka signifikansi sebesar 0,236. Nilai Sig sebesar 0,236 > 0,05 maka terdapat pengaruh kebijakan rekrutmen peserta didik $\left(\mathrm{X}_{1}\right)$ positif dan signifikan terhadap prestasi belajar siswa (Y).

Untuk mengetahui besar kecilnya sumbangan variabel $\mathrm{X}_{1}$ terhadap $\mathrm{Y}$ dilakukan dengan menghitung besarnya koefisien determinasi. Atau bisa dilihat dari hasil olah data dengan SPSS version 22 for window pada tabel 2 berikut:

Tabel 2 Koefisien Determinasi Variabel $X_{1}$ terhadap $Y$

\begin{tabular}{|l|c|c|c|c|}
\hline & $\mathrm{R}$ & $\mathrm{R}$ Squared & Eta & Eta Squared \\
\hline $\begin{array}{l}\text { Prestasi Belajar Siswa * } \\
\text { Kebijakan Rekrutmen Peserta } \\
\text { Didik }\end{array}$ &, 155 &, 024 &, 388 &, 151 \\
\hline
\end{tabular}


Dari tabel 2 diketahui bahwa $\mathrm{R}$ sebesar 0,155. Ini berarti koefisien determinasi $=r^{2} \times 100 \%=(0,155)^{2} \mathrm{x}$ $100 \%=0,024 \times 100 \%=2,4 \%$, artinya variabel $\mathrm{Y}$ dipengaruhi oleh variabel $\mathrm{X}_{1}$ sebesar 2,4\% dan sisanya $97,6 \%$ dipengaruhi oleh variabel $\mathrm{X}_{2}$ dan variabel lain yang tidak diteliti dalam penelitian ini. Untuk mengetahui besaran pengaruh variabel manajemen sarana prasarana $\left(\mathrm{X}_{2}\right)$ terhadap prestasi belajar siswa (Y) dilakukan dengan uji regresi linear dengan menggunakan SPSS version 22 for window

Tabel 3 Koefisien Regresi dan Uji signifikansi secara Parsial $\mathbf{X}_{2}$

\begin{tabular}{|c|c|c|c|c|c|c|}
\hline & \multirow[t]{2}{*}{ Model } & \multicolumn{2}{|c|}{ Unstandardized Coefficients } & $\begin{array}{l}\text { Standardized } \\
\text { Coefficients }\end{array}$ & \multirow[t]{2}{*}{$\mathrm{T}$} & \multirow[t]{2}{*}{ sig. } \\
\hline & & $\mathrm{B}$ & Std. Error & Beta & & \\
\hline \multirow[b]{2}{*}{1} & (Constant) & 58.493 & 10.580 & & 5.529 & .000 \\
\hline & $\begin{array}{l}\text { Manajemen Sarana } \\
\text { Prasarana }\end{array}$ & .966 & .102 & .778 & 9.429 & .000 \\
\hline
\end{tabular}

Persamaan regresi dari hasil perhitungan diperoleh $\widehat{y}==\mathrm{a}+\mathrm{bx}$, atau $\widehat{y}==58,493+0,966 X_{2}$. Konstanta sebesar 58,493 menyatakan bahwa jika tidak ada kenaikan nilai dari variabel manajemen sarana prasarana $\left(\mathrm{X}_{2}\right)$, maka prestasi belajar siswa (Y) adalah 58,493. Koefisien regresi 0,966 menyatakan bahwa setiap perubahan satu skor nilai manajemen sarana prasarana maka akan memberikan kenaikan skor kinerja guru sebesar 0,966 unit.

Kemudian pengujian signifikansi dilakukan dengan memperhatikan data pada tabel 3 diketahui angka signifikansi sebesar 0,000. Nilai Sig sebesar 0,000< 0,05 maka terdapat pengaruh manajemen sarana prasarana $\left(\mathrm{X}_{2}\right)$ positif dan signifikan terhadap prestasi belajar siswa (Y).

Sedangkan untuk mengetahui besar kecilnya sumbangan variabel $\mathrm{X}_{2}$ terhadap Y dilakukan dengan menghitung besarnya koefisien determinasi. Atau bisa dilihat dari hasil olah data dengan SPSS version 22 for window pada tabel 3 berikut:

Tabel 4 Koefisien Determinasi Variabel $X_{2}$ terhadap $Y$

\begin{tabular}{|l|c|c|c|c|}
\hline & $\mathrm{R}$ & $\mathrm{R}$ Squared & Eta & Eta Squared \\
\hline $\begin{array}{l}\text { Manajemen Sarana Prasarana * } \\
\text { Motivasi Kerja Guru }\end{array}$ &, 778 &, 605 &, 953 &, 908 \\
& & & & \\
\hline
\end{tabular}


Dari tabel 4 diketahui bahwa $\mathrm{R}$ Square sebesar 0,605. Ini berarti koefisien determinasi $=r^{2} \times 100 \%=(0,778)^{2} \mathrm{x}$ $100 \%=0,605 \times 100 \%=60,5 \%$, artinya variabel $\mathrm{Y}$ dipengaruhi oleh variabel $\mathrm{X}_{2}$ sebesar $60,5 \%$ dan sisanya sebesar $39,5 \%$ dipengaruhi oleh variabel $\mathrm{X}_{1}$ dan variabel lain yang tidak diteliti dalam penelitian ini.

Tabel 5 Koefisien Regresi dan Uji signifikansi secara Simultan

\begin{tabular}{|c|c|c|c|c|c|c|}
\hline & \multirow[t]{2}{*}{ Model } & \multicolumn{2}{|c|}{$\begin{array}{c}\text { Unstandardized } \\
\text { Coefficients }\end{array}$} & $\begin{array}{l}\text { Standardized } \\
\text { Coefficients }\end{array}$ & \multirow[t]{2}{*}{$\mathrm{t}$} & \multirow[t]{2}{*}{ sig. } \\
\hline & & $\mathrm{B}$ & Std. Error & Beta & & \\
\hline \multirow[t]{3}{*}{1} & (Constant) & 83.657 & 52.832 & & 1.583 & .119 \\
\hline & Rekrutmen Peserta Didik & -.315 & .647 & -.042 & .486 & .629 \\
\hline & $\begin{array}{l}\text { Manajemen Sarana } \\
\text { Prasarana }\end{array}$ & .979 & .106 & .788 & 9.191 & .000 \\
\hline
\end{tabular}

Untuk menguji pengaruh variabel kebijakan rekrutmen peserta didik $\left(\mathrm{X}_{1}\right)$ dan variabel manajemen sarana prasarana $\left(\mathrm{X}_{2}\right)$ secara bersama-sama terhadap prestasi belajar siswa (Y) dengan dilakukan uji regresi linear berganda menggunakan SPSS version 22 for window, diperoleh hasil seperti yang disajikan pada tabel 5 dan dapat diketahui bahwa $\mathrm{Y}=83,657-0,315 \mathrm{X}_{1}+$ $0,979 \mathrm{X}_{2}$.Konstanta sebesar 83,657 menyatakan bahwa jika tidak ada kenaikan nilai dari variabel kebijakan rekrutmen peserta didik $\left(\mathrm{X}_{1}\right)$ dan manajemen sarana prasarana $\left(\mathrm{X}_{2}\right)$ maka prestasi belajar siswa (Y) adalah 83,657.
Koefisien regresi sebesar -0,315 dan 0,979 menyatakan bahwa setiap perubahan satu skor atau nilai kebijakan rekrumen peserta didik dan manajemen sarana prasarana maka akan memberikan kenaikan skor 0,315 dan 0,979 unit pada prestasi belajar siswa.

Untuk mengetahui adanya pengaruh positif dan berapa besar pengaruh kebijakan rekrutmen peserta didik $\left(\mathrm{X}_{1}\right)$ dan manajemen sarana prasarana $\left(\mathrm{X}_{2}\right)$ secara bersama-sama terhadap prestasi belajar siswa SMA Negeri di K3S V wilayah Haurgeulis Kabupaten Indramayu dilakukan uji korelasi ganda dengan hasil seperti tertera pada tabel 6 berikut ini.

Tabel. 6 Perhitungan Uji Regresi Ganda

\begin{tabular}{|c|c|c|c|c|c|c|c|c|c|}
\hline \multirow{2}{*}{ Model } & \multirow{2}{*}{$\mathrm{R}$} & \multirow{2}{*}{$\begin{array}{c}\mathrm{R} \\
\text { Square }\end{array}$} & $\begin{array}{c}\text { Adjusted } \mathrm{R} \\
\text { Square }\end{array}$ & $\begin{array}{c}\text { Std. Error } \\
\text { of the } \\
\text { Estimate }\end{array}$ & $\begin{array}{c}\text { R Square } \\
\text { Change }\end{array}$ & F Change & df1 & df2 & $\begin{array}{c}\text { Sig. F } \\
\text { Change }\end{array}$ \\
\hline
\end{tabular}




\begin{tabular}{|c|c|c|c|c|c|c|c|c|c|}
\hline 1 & $.779^{a}$ & .607 & .593 & 13.295 & .607 & 43.987 & 2 & 57 & .000 \\
\hline
\end{tabular}

Berdasarkan hasil tabel 6 di atas, dapat dilihat besarnya hubungan korelasi ganda antara variabel kebijakan rekrutmen peserta didik $\left(\mathrm{X}_{1}\right)$ dan manajemen sarana prasarana $\left(\mathrm{X}_{2}\right)$ secara bersama-sama terhadap prestasi belajar siswa $(\mathrm{Y})$ sebesar 0,779 . Hal ini menunjukkan pengaruh yang positif antara kebijakan rekrutmen peserta didik dan manajemen sarana prasarana secara bersama-sama terhadap prestasi belajar siswa. Sedangkan untuk mengetahui prosentase sumbangan pengaruh variabel kebijakan rekrutmen peserta didik $\left(\mathrm{X}_{1}\right)$ dan manajemen sarana prasarana $\left(\mathrm{X}_{2}\right)$ secara bersama-sama terhadap variabel prestasi belajar siwa (Y). Dengan memperhatikan tabel 6 diperoleh angka $\mathrm{R}^{2}$ ( $\mathrm{R}$ square) sebesar 0,607. Hal ini menunjukkan bahwa prosentase sumbangan pengaruh variabel $\mathrm{X}_{1}$ dan $\mathrm{X}_{2}$ terhadap variabel $\mathrm{Y}$ sebesar $60,7 \%$. Sedangkan sisanya $39,3 \%$ dipengaruhi oleh variabel lain yang tidak dimasukkan dalam penelitian ini.

\section{Pembahasan}

$$
\begin{aligned}
& \text { Berdasarkan hasil penelitian } \\
& \text { bahwa ketika satuan pendidikan } \\
& \text { melakukan proses rekrutmen peserta didik }
\end{aligned}
$$

melalui kegiatan penerimaan peserta didik baru (PPDB) maka proses seleksi peserta didik akan sangat mempengaruhi prestasi belajar siswa, kalau dalam proses ini satuan pendidikan secara asal-asalan menerima peserta didik baru tanpa seleksi yang ketat, secara empirik hasil penelitian ini menginformasikan : 1) terdapat pengaruh yang signifikan kebijakan rekrutmen peserta didik terhadap prestasi belajar siswa sekolah menengah atas negeri di kelompok kerja kepala sekolah (K3S) wilayah Haurgeulis Kabupaten Indramayu, serta 2) besarnya pengaruh yang signifikan kebijakan rekrutmen peserta didik terhadap prestasi belajar siswa sekolah menengah atas negeri di kelompok kerja kepala sekolah (K3S) wilayah Haurgeulis Kabupaten Indramayu ditunjukkan oleh hasil penelitian bahwa rekrutmen peserta didik yang terdiri dari dimensi : (1) Mencari para pelamar yang memiliki kompetensi, (2) Menemukan para pelamar yang memiliki kompetensi, dan (3) Menarik para pelamar yang memiliki kompetensi. (Nurul Ulfatin dan Teguh Triwiyanto, 2012:50). Jika dipadukan antara teori dengan hasil penelitian menunjukkan bahwa realita di lapangan sangat relevan, ini dibuktikan 
dengan data pada tabel 5 bahwa variabel kebijakan rekrutmen peserta didik dengan nilai $\mathrm{t}=0,486$ dan sig. $=0,01<0,05$, kebijakan rekrutmen peserta didik sangat berpengaruh terhadap prestasi belajar siswa.

Manajemen sarana prasarana tidak kalah pentingnya mempengaruhi prestasi belajar siswa, hal ini dapat dilihat pada satuan pendidikan atau sekolah yang sudah memiliki saranan parasarana yang lengkap baik sarana prasarana yang terlibat langsung dengan pembelajaran siswa di kelas maupun sarana prasarana yang menunjang kegiatan non akademik. Menurut pendapat Suhaeli (2011:147) dikatakan bahwa "Usaha meningkatan mutu proses pendidikan perlu didukung oleh tersedianya sarana dan prasarana yang memadai, baik jumlah maupun mutunya."

Secara empirik hasil penelitian ini menginformasikan: 1) terdapat pengaruh yang signifikan manajemen sarana prasarana terhadap prestasi belajar siswa sekolah menengah atas negeri di kelompok kerja kepala sekolah (K3S) wilayah Haurgeulis Kabupaten Indramayu, serta 2) besarnya pengaruh yang signifikan manajemen sarana prasarana terhadap prestasi belajar siswa sekolah menengah atas negeri di kelompok kerja kepala sekolah (K3S) wilayah Haurgeulis Kabupaten Indramayu ditunjukkan oleh hasil penelitian bahwa manajemen sarana prasarana yang terdiri dari dimensi : (1) Kemampuan untuk perencanaan kebutuhan sarana prasarana, (2) Kemampuan untuk pengadaan Sarana prasarana, (3) Kemampuan untuk penyimpanan sarana prasarana, (4) Kemampuan untuk penginventarisasian sarana prasarana, (5) Kemampuan pemeliharaan sarana prasarana, dan (6) Kemampuan penghapusan sarana dan prasarana. (Rohiat 2008 :26). Jika dipadukan antara teori dengan hasil penelitian menunjukkan bahwa realita di lapangan sangat relevan, hal ini dibuktikan dengan data pada tabel 5 bahwa variabel manajemen sarana prasarana dengan nilai $\mathrm{t}=9,191$ dan sig. $=$ $0,00<0,05$, manajemen sarana prasarana sangat berpengaruh terhadap prestasi belajar siswa.

Pengujian signifikansi untuk perhitungan regresi di gunakan uji $\mathrm{F}$ dari data pada tabel 6 menunjukkan bahwa $F_{\text {hitung }}$ sebesar 43,987 dan untuk $F_{\text {tabel }}$ sebesar 4,007 sehingga diketahui bahwa $\mathrm{F}_{\text {hitung }}>\mathrm{F}_{\text {tabel }}$, artinya terdapat pengaruh yang signifikan antara kebijakan rekrutmen peserta didik dan manajemen sarana prasarana secara bersama-sama terhadap prestasi belajar siswa, menurut Kingsley (Sudjana, 2014:45) 
mengemukakan bahwa: "Membagi tiga macam prestasi belajar, yaitu: a) keterampilan dan kebiasaan b) pengetahuan dan pengertian c) sikap dan cita-cita yang masing-masing golongan dapat diisi dengan bahan yang ada pada kurikulum sekolah". Hasil penelitian ini menunjukkan bahwa ada pengaruh positif dan signifikan kebijakan rekrutmen peserta didik dan manajemen sarana prasarana secara parsial maupun secara bersama-sama terhadap prestasi belajar siswa.

\section{Kesimpulan}

Berdasarkan hasil penelitian dan pembahasan yang telah dilakukan maka dapat diambil kesimpulan sebagai berikut:

1. Terdapat pengaruh positif dan signifikan antara kebijakan rekrutmen peserta didik terhadap prestasi belajar siswa di sekolah menengah atas negeri pada kelompok kerja kepala sekolah (K3S) Wilayah Haurgeulis Kabupaten Indramayu, dengan besaran pengaruh $15,5 \%$.

2. Terdapat pengaruh positif dan signifikan antara manajemen sarana prasarana terhadap prestasi belajar siswa di sekolah menengah atas negeri pada kelompok kerja kepala sekolah (K3S) Wilayah Haurgeulis
Kabupaten Indramayu, dengan besaran pengaruh $77,8 \%$.

3. Terdapat pengaruh positif dan signifikan antara kebijakan rekrutmen peserta didik dan manajemen sarana prasarana secara simultan terhadap prestasi belajar siswa di sekolah menengah atas negeri pada kelompok kerja kepala sekolah (K3S) Wilayah Haurgeulis Kabupaten Indramayu, dengan besaran pengaruh $77,9 \%$.

\section{DAFTAR PUSTAKA}

Amran, A. (2015). Faktor Penentu Keberhasilan Pengelolaan Satuan Pendidikan. Manajer Pendidikan, 9(2).

Hamidah, D. (2018). Manajemen Peseta Didik. Jurnal Serunai Administrasi Pendidikan, 6(2).

Dekawati, I. (2018). Implementasi Pengelolaan Sarana Dan Komunikasi Organisasi Serta Kontribusinya Terhadap Mutu Pelayanan Pendidikan. Edum Journal, 1(2), 69-75.

Efferi, A. (2019). Strategi Rekrutmen Peserta Didik Baru Untuk Meningkatkan Keunggulan Kompetitif di MA Nahdlotul Muslimin Undaan Kudus. Edukasia: Jurnal Penelitian Pendidikan Islam, Vol. 14, No. 1, Februari 2019

Prastyawan. (2016). Manajemen Sarana Dan Prasarana Pendidikan. $A L$ HIKMAH Jurnal Studi Keislaman, 6(1). 
Pratomo, P., Suwitri, S., \& Subowo, A. (2013). Analisis Dampak Kebijakan Penerimaan Peserta Didik Sekolah Menengah Pertama 3 Semarang (Kajian Peraturan Kepala Dinas Pendidikan Kota Semarang 420/3271 Tentang Petunjuk Teknis Penerimaan Peserta Didik Reguler Di Kota Semarang

Putri, D. A. K., \& Adi, B. W. (2016). Pengaruh Sarana Prasarana Sekolah Dan Motivasi Belajar Siswa Terhadap Prestasi Belajar Siswa Pemasaran Di Smk Negeri 1 Sukoharjo Tahun Ajaran 2015/2016. Jurnal Pendidikan Bisnis dan Ekonomi, 2(2).

Rosivia, R. (2014). Peningkatan pengelolaan sarana prasarana pendidikan di smp negeri 10 padang (Doctoral dissertation, Universitas Negeri Padang).

2010/2011). Journal of Public Policy and Management Review, 2(4), 97-105.

Rohiat. (2008). Manajemen Sekolah Teori Dasar dan Praktik. Bandung : Refika Aditama.

Sudjana, N. (2014). Dasar-dasar Proses Belajar Mengajar. Bandung: Sinar Baru Algesindo.

Suhaeli. (2011). Effective School. Indramayu : PGRI Kabupaten Indramayu.

Ulfatin, N, dkk.(2016). Manajemen Sumber Daya Manusia Bidang Pendidikan. Jakarta : PT. Raja Grafindo Persada. 